\title{
Interview data on severe behavioural eating difficulties in young children
}

\author{
J E Douglas, M Bryon
}

\begin{abstract}
Interview data from parents of 201 children under age 7 years with severe feeding and eating difficulties were analysed to describe features in the child's and parents' experiences that may have contributed to the development of the eating problem. Prematurity and low birth weight, distress during feeding in the first six months of life, and regular or frequent vomiting were common findings in the histories of the children. Aversive experiences during feeding may be the basis for early childhood eating difficulties.

(Arch Dis Child 1996;75:304-308)
\end{abstract}

Keywords: feeding, eating, behaviour.

Feeding and eating difficulties in young children are common and it is important to recognise these at an early age and provide support for parents to help them cope with their child's eating.

Attempts to classify these eating difficulties have tended to oversimplify the issues and focus on 'organic' and 'non-organic' failure to thrive. Several studies have identified serious behavioural eating difficulties in young children who have experienced ill health or tube feeding early in life. ${ }^{1-7}$ Children can also be inaccurately diagnosed as having 'non-organic failure to thrive' when they have undiagnosed oral sensorimotor impairment from birth or early in life. ${ }^{8}$

Young children and their parents may require psychological help to overcome eating difficulties that have become established during a period of medical or surgical treatment and which may continue long after the initial event has resolved.

A psychological treatment programme has been established in Great Ormond Street Hospital for Children. A semistructured diagnostic interview was designed to collect standard information to aid classification and understanding of those referred and to identify any predictors of severe behavioural feeding problems.

Psychological

Medicine, Great

Ormond Street

Hospital for Children

NHS Trust, Great

Ormond Street,

London WC1N 3JH

J E Douglas

M Bryon

Correspondence to: JE Douglas.

Accepted 9 July 1996 under 7 years and have had a severe eating difficulty for at least six months. Half of the sample were referred from within the hospital
(51\%) while the rest were referred from paediatricians, general practitioners, and community health services.

\section{MEASURES}

Each child was assessed from a semistructured interview with parents by trained assistant psychologists who had either watched videos of previous interviews or sat in on interviews with other psychologists. Ten assistant psychologists or clinical staff conducted the interviews. No reliability measures were obtained. Uncertainties about any of the interviews were clarified during review between the parents and the senior author. In addition, a video was taken of parents and child eating lunch together in the unit, several questionnaires were given to the parents, and each child's height and weight were measured. We present here only the interview data obtained from questions which were designed with immediate scoring on predefined multiple choice and yes/no answers (available from the authors). Areas covered included family demographic data, parental mental health and eating patterns, social support, life events, child care arrangements, birth and medical history, child's development, sleep and behaviour problems, history of the eating problem and related medical factors, history of tube feeding, additional behaviours related to feeding, and child's current feeding pattern.

Over the course of five years some questions were dropped and others added as we became aware of the importance of certain information. In these instances the reduction of the sample size is indicated. The percentages quoted are valid as there were varying amounts of missing data for differing questions. Missing data at a level greater than $10 \%$ are reported.

\section{Results}

DEMOGRAPHIC DATA

The mean age was 37.25 months (median 33 months, range 4 to 100 months), the greatest number of cases being between 1 and 3 years of age; $56 \%$ were boys and $44 \%$ girls. Eighty five per cent of the children lived with both natural parents, while $12 \%$ lived with a single mother. Sixteen per cent of the mothers and $87 \%$ of the fathers were employed ( 26 cases not known). The social class of each family based on father's current or previous occupation (Office of Population Censuses and Surveys, 1991) were: $39 \%$ class I and II, $48 \%$ class III (manual and non-manual), and $13 \%$ class IV and V. 
Table 1 Frequency and percentages of medical problems experienced by the children with eating difficulties

\begin{tabular}{lll}
\hline Medical problem & No & Valid \% \\
\hline Ear, nose, and throat problems & 59 & 32 \\
Ophthalmic problems (sample = 82) & 20 & 26 \\
Tracheo-oesophageal fistula & 11 & 6 \\
Gastro-oesophageal reflux & 80 & 41 \\
Abdominal surgery & 6 & 3 \\
Hiatus hernia & 20 & 11 \\
Coeliac disease & 1 & 1 \\
Pyloric stenosis & 10 & 6 \\
Metabolic disorder/problems & 10 & 5 \\
Cardiac problems & 26 & 14 \\
Cancer & 0 & 0 \\
Renal problems & 19 & 10 \\
Syndromes-eg Noonan's, Down's & 20 & $11^{\star}$ \\
Congenital malformation & 19 & 10 \\
Immunological problems & 13 & $7^{\star}$ \\
Neurological problems & 18 & 10 \\
Respiratory problems (sample $=82)$ & 24 & 29 \\
\hline ॠ & &
\end{tabular}

$\star$ For 22 cases data missing.

\section{MEDICAL CHARACTERISTICS}

Birth data

Feeding difficulties are common in premature and low birth weight infants. ${ }^{9}$ Nearly a quarter of the children referred (22\%) had been born early, $15 \%$ with a gestational age between 30 and 36 weeks, and an additional $7 \%$ born at less than 30 weeks.

Mean birth weight was $2800 \mathrm{~g}$ (SD $898 \mathrm{~g}$ ) with one third (33\%) below $2500 \mathrm{~g} ; 7 \%$ of United Kingdom infants are of low birth weight and $1 \%$ very low birth weight. ${ }^{10}$

Fifty eight per cent of the children were delivered vaginally and $28 \%$ by caesarean section. Forty nine per cent of the sample required special care after delivery. For the 36 parents asked, the length of time in special care averaged of 39 days (median 20 days, range 1 to 175 days).

\section{Medical problems}

Seventy six per cent of the children had been diagnosed as having at least one significant medical problem in their early history (table 1). 'Syndrome' in this table refers to various metabolic and genetic disorders, including Russell-Silver, Noonan's, Williams', Kabuki make-up, Down's, etc. Many of the children had experienced more than one listed problem and all of the medical difficulties could have had an effect on the development of the child's eating.

Seventy nine per cent of the sample had been inpatients, with an average of five admissions (median 3, range 50) and an average total time in hospital of 88 days (45 cases not known; SD 145).

\section{DEVELOPMENT}

Motor milestones

Over one third showed mild or severe delay in attaining motor milestones. This information was gathered through retrospective parental report and observation of the child. Parents were asked to indicate the age at which their child sat unsupported, walked, talked, and was dry in the day. Defined age bands in months that correlate with categorisations of no delay, mild delay, severe delay, or too young to record were listed for immediate scoring. We recognise that this is not a definitive assessment but reflects the information gathered by most clinicians during initial interviews.

Seventeen per cent showed mild (8 to 10 months) and $23 \%$ severe delay ( $11+$ months) in sitting, while $15 \%$ showed a mild (19 to 24 months) and $17 \%$ severe delay (2+ years) in walking. Twelve per cent showed a mild (30 to 36 months) and $18 \%$ severe delay (36+ months) in toilet training. We excluded those who were too young to be analysed on these developmental milestones $(1 \%, 10 \%$, and $40 \%$ respectively).

\section{Oral-motor difficulties and language}

When a child is refusing to eat or only eats limited textures it is difficult to assess whether they have oral motor difficulties. One possible avenue is to identify the incidence of speech delay. Nineteen per cent of the children showed mild delay (single words at 2 to 3 years) and $10 \%$ severe delay (no words before 3 years) in talking, as reported by parents or observed in the child (18\% of the children were too young to be rated). This is high compared to the normal population of under fives in whom $10 \%$ have been described as having speech problems excluding speech dysfluency. ${ }^{9}$ In another study of 7053 year olds, 3.1\% had expressive language delay six months or more behind their chronological age. ${ }^{11}$ Difficulties in speech and articulation could indicate oralmotor immaturity or could be related to general developmental delay.

Many of the children had shown a reluctance to experience oral stimulation in infancy. Out of 82 families asked, one third of the children had never sucked their fingers or thumbs and a quarter seriously refused to have their teeth brushed. Twenty two per cent of the children were reluctant to explore objects orally, for example never having put toys in their mouths.

\section{BEHAVIOUR}

\section{Behaviour problems}

Out of 135 parents who were asked, $42 \%$ described their child as having mild behaviour problems (for example, more tantrums than usual for age), while only $3 \%$ were described as having serious behavioural problems (for example, frequent tantrums, poor concentration, problems at nursery/school). This is higher than estimates in an urban population, where $21 \%$ of preschool children were described by parents as having mild/moderate behaviour problems and $1 \%$ severe behaviour problems. ${ }^{11}$ Our method of data collection was different and parents could have overestimated the severity. It will be important to verify parent opinion against the scores on the behaviour checklist collected at the same time.

We speculate that the high incidence of early illness in these children may have influenced parents' emotional state and led to changes in child management resulting in behaviour problems. Alternatively a child's medical problems may relate directly to the increased incidence of behavioural problems. Premature infants and those with perinatal difficulties have been found previously to show increased rates of behavioural disturbance. ${ }^{12}$ 
When the incidence of behavioural problems (excluding feeding and sleeping problems) in the children who had medical problems (as listed in table $1, \mathrm{n}=102$ ) was compared with those who had no diagnosed medical problems ( $n=26$, no significant difference in the parents' rating of their child's behaviour was found $\left(\chi^{2}, p=0.71\right)$. It appears therefore that the child's medical history is not related to the incidence of behavioural problems.

\section{Sleeping problems}

Sleeping problems are the most commonly reported behavioural problem in young children and often reflect parents' difficulties in setting limits for their child. ${ }^{13}$ Out of 82 families who were asked, $33 \%$ of the parents indicated that their child had a sleeping problem. Eighteen per cent described this as mild (regular waking but not every night) while $17 \%$ described it as a serious problem (wakes every night or sleeps in parents' bed nightly). This is higher than the level of sleeping problems expected in a normal population. In one study of 3 year olds, $5.5 \%$ of a control group woke at night ( $3+$ times per week) and $3.3 \%$ slept in their parent's bed, as compared to $17.2 \%$ of a behaviour problem group who woke at night and $17.2 \%$ who slept in their parents' bed. " Although the data were not collected in an identical manner, both studies used parental report and the average age of the children in that study was 3 years.

We analysed whether the incidence of sleeping problems was higher in children with no diagnosed medical problems than in those with a medical problem. There was no significant difference between the two groups $\left(\chi^{2}, \mathrm{p}=\right.$ 0.87 ), indicating that the higher level of sleep problems in this sample is not related to the incidence of medical problems.

FEEDING EXPERIENCES

The children's feeding histories provided extensive evidence of unpleasant or distorted experiences associated with feeding. ${ }^{12}$

\section{Distress while feeding}

Over half of the mothers (62\%) described their babies' distress on feeding in the first three months of life, with $30 \%$ of the total sample showing marked distress, including refusal to feed and being tube fed. Similarly, $67 \%$ of the mothers reported infant distress during feeding from 3 to 6 months of age.

Weaning also produced difficulties, with over half of the children $(60 \%)$ refusing stage 1

Table 2 Length of time the children were tube fed

\begin{tabular}{|c|c|c|c|c|c|c|}
\hline \multirow{2}{*}{ Length of time tube fed } & \multicolumn{2}{|c|}{ NG $(n=122)$ valid } & \multicolumn{2}{|c|}{$G T(n=42) *$ valid } & \multicolumn{2}{|c|}{$T P N(n=36)$ valid } \\
\hline & No & $\%$ & No & $\%$ & No & $\%$ \\
\hline $\begin{array}{l}\text { Less than } 1 \text { month } \\
1-3 \text { months } \\
3-6 \text { months } \\
6-18 \text { months } \\
\text { More than } 18 \text { months }\end{array}$ & $\begin{array}{l}32 \\
16 \\
18 \\
36 \\
19\end{array}$ & $\begin{array}{l}26 \\
13 \\
15 \\
30 \\
16\end{array}$ & $\begin{array}{r}1 \\
3 \\
4 \\
10 \\
16\end{array}$ & $\begin{array}{r}3 \\
9 \\
12 \\
29 \\
47\end{array}$ & $\begin{array}{r}18 \\
6 \\
3 \\
6 \\
0\end{array}$ & $\begin{array}{r}55 \\
18 \\
9 \\
18 \\
0\end{array}$ \\
\hline
\end{tabular}

^ For 8 cases data missing.

$\mathrm{NG}=$ nasogastric tube; $\mathrm{GT}=$ gastrostomy tube; $\mathrm{TPN}=$ total parenteral nutrition. pureed baby foods, and a quarter of the children $(24 \%)$ still refusing to eat them at the time of referral to the feeding programme. Stage 1 foods were introduced at an average age of 5 months (SD 3.5 months).

Weaning onto stage 2 textured baby foods also caused considerable distress. Out of $\mathbf{8 2}$ families asked, $59 \%$ of the children had refused these foods and $39 \%$ were still doing so at the time of referral. Parents reported gagging, choking, retching, and spitting food, with avoidance and crying if the food was persistently offered.

The association between feeding problems occurring at 0-3 months and continuing into the 3-6 months period was extremely high in 183 cases (relative odds $=30.95,95 \%$ confidence interval 12.82 to 74.73; Yule's $Q=$ $0.94)$. For the whole sample, feeding problems commenced on average at the age of 5 months (SD 9.2).

\section{Vomiting}

Parents reported that $70 \%$ of the children had vomited regularly or frequently $(41 \%$ associated with diagnosed gastro-oesophageal reflux). Vomiting began at an average age of 5 months (SD 7.7) and 45\% had continued for more than 12 months. Forty four per cent vomited at least four times daily and half had received treatment for this ( $21 \%$ surgical, $34 \%$ medical).

\section{Tube feeding}

One third of the sample $(34 \%)$ had experienced tube feeding during their first six months of life, $8 \%$ having been tube fed exclusively (table 2). Of 127 patients, over half $(63 \%)$ had experienced it at some time. Of those who had been tube fed, $97 \%$ had nasogastric tubes, 33\% had gastrostomy tubes, and $28 \%$ had total parenteral nutrition. Individual children had often been fed by two or three different types of tube feeding.

The severity and chronicity of feeding problems in this sample is indicated by the fact that $38 \%$ of the children had been fed by gastrostomy for more than 18 months. Forty per cent were still tube fed at the time of referral. Out of a group of 31 tube feeders who were questioned, $71 \%$ received all their nutrition by tube while $26 \%$ received half by tube. The experience of continuing to eat and drink while being tube fed may be important in maintaining the learned skills of eating different textures and coping with different tastes. ${ }^{14}$ During the periods of tube feeding, $35 \%$ had continued to eat orally most or all of the time, $55 \%$ for some of the time, and $10 \%$ not at all. More of the children had maintained some form of drinking, with $42 \%$ continuing to drink most or all of the time, another $42 \%$ some of the time, and $16 \%$ not at all.

Children tube fed at assessment were not necessarily of low birth weight. There was no significant difference in incidence in 61 children who had a birth weight of less than 2500 g compared to 129 children with a birth weight of over $2500 \mathrm{~g}\left(\chi^{2}, \mathrm{p}=0.3\right)$. 
Table 3 Frequencies and percentages of types of children's feeding problems

\begin{tabular}{lll}
\hline Problem & No & Valid \% \\
\hline Inappropriate texture for age & 91 & 50 \\
Inadequate quantity eaten & 142 & 78 \\
Disinterest in food & 114 & 63 \\
Vomiting/regurgitating (daily) & 62 & 34 \\
Selective eating & 60 & 34 \\
Slow eater & 95 & 56 \\
Holds/stores food in mouth (daily) & 91 & 53 \\
Does not chew & 64 & 34 \\
Gags/chokes/spits food out (daily) & 118 & 67 \\
\hline
\end{tabular}

TYPES OF FEEDING PROBLEM

Most common was inadequate quantity eaten by the child ( $78 \%)$. Severe selective eating was present in a third of the total sample while a half had problems with eating different textures. Table 3 shows the range of eating problems described by the parents, but the categories are not mutually exclusive, that is, children who eat inappropriate textures for their age are more likely not to chew but show gagging and spitting, while children who eat an inadequate quantity are more likely to be slow, store food in their mouths, and be disinterested.

FAMILY EMOTIONAL STATE

Parenting style and mental health status may contribute to the development or maintenance of a child's eating problem.

\section{Parenting style}

We postulated that an increased incidence of eating problems in the siblings of children with eating difficulties could indicate a general effect of parenting style on their children's eating.

Parents' descriptions of the eating pattern of siblings $(n=138)$, indicated that $23 \%$ had also had difficulties with eating ( $22 \%$ slight, $1 \%$ severe). This is no higher than expected in retrospective information from parents on eating behaviour of preschool children. One third of 5 year olds in the normal population are described as having mild or moderate eating or appetite problems by their parents. ${ }^{9}$

\section{Parenting stress}

Most parents (90\%) felt that their child's feeding problem had a significant impact on their family life, $70 \%$ describing this as moderate to severe. The stress experienced by parents was related to the child's eating and not to general life stresses. Ninety four families were questioned and reported that they had not been unduly stressed by life events in the previous year to referral. A list of 19 life events taken from the Parenting Stress Index were used. ${ }^{15}$ They had an average of 1.06 life events (SD 1.49).

\section{Parental depression}

A higher incidence of maternal depression has been linked to the incidence of non-organic failure to thrive in children ${ }^{16}{ }^{17}$ and with the incidence of behaviour problems in young children, ${ }^{11}$ but a causative relation has not been established.
One third $(33 \%)$ of the mothers in this sample described themselves as having experienced periods of depression in the past on a simple yes/no answer. Further questioning listed a range of treatment for depression. This is at a level expected in the general population for mothers of young children. ${ }^{18}$

Fourteen per cent described themselves as depressed at interview, this appears low in the context of the high level of stress felt by mothers about their child's eating problem.

We hypothesised that the level of depression reported by mothers may have been due to the strain of caring for an ill child but an analysis of the incidence of self reported maternal depression (past or present) in 180 mothers of children with a medical history $(n=131)$ compared to those without a medical history $(n=43)$ showed no significant difference $\left(\chi^{2}\right.$, $\mathrm{p}=0.29$ ). Therefore, level of depression may be related to the strain of caring for preschool children rather than any particular stress caused by the child's ill health.

Of the 82 fathers questioned, only $4 \%$ reported past depression and $2 \%$ current depression.

\section{Maternal eating attitudes}

Research has recently found that feeding disturbances in children are specifically associated with disturbed eating habits and attitudes among mothers. ${ }^{19}$

Over a third of mothers (38\%) in this sample were trying to control their weight or put on weight at the time of referral $(35 \%$ were occasional dieters, while $3 \%$ were frequent dieters). Forty two per cent of mothers reported dieting in the past ( $11 \%$ frequently). This may not be unusually high in comparison to the general population. Only brief questions were asked about this issue in the interview and mothers may have disguised the severity of their own level of disturbance. This issue requires further investigation and more sensitive questioning.

Fathers were less concerned about their weight, with $15 \%$ currently trying to diet, $1 \%$ frequently.

\section{Discussion}

In our attempt to identify aetiological factors in the development of eating problems, we have been progressively guided away from aspects of family functioning or parenting and more towards factors related to the child.

Our sample had a slightly higher incidence of general behaviour problems and sleeping problems than expected in the normal population, and also showed higher levels of developmental delay and speech delay.

Notable features in the data gathered were the very early ages at which children first showed feeding difficulties and the aversive experiences that these children have associated with eating. Frequent and long lasting vomiting was very common in the first year of life, during which avoidance learning seems to have become well established. 
Distortion of the child's opportunity to learn how to eat and experience tastes and textures may be developmentally important. Managing tube feeding to encourage oral stimulation with some oral intake, if medically appropriate, may ease transition to eventual tube removal. It is still not clear why some tube fed children have difficulty in transferring to oral feeding when the tube is no longer required.

When tube feeding is instigated purely to supplement a child's nutritional status then psychological management is necessary so that tube feeding is not seen as a treatment in itself but as nutritional maintenance while eating is established and improved.

When family factors were examined, siblings were not reported to have a greater level of eating problems than expected. Therefore, we found no indication of distorted family patterns concerning eating. Maternal eating attitudes may be important but further studies are needed to determine whether they are significant in this group of children.

Parents reported high stress levels but this was related to attributes of the child rather than any family or marital problems. Mothers' self reports of depression were no greater than expected for mothers of preschool children.

This descriptive study indicates the importance of children's early experience with eating which can have long lasting effects. Possible risk factors that we identified as associated with severe and chronic feeding problems in this sample of young children were as follows: (1) low birth weight; (2) developmental delay (including motor and language delay); (3) early onset of the feeding problem ( 0 to 3 months); (4) a history of frequent vomiting of long duration.
Our great appreciation to Jonna Kuntsi, Deborah Slocum Brigit Hulson, and other assistant psychologists who laboured over the data base to enter data and carry out the analyses.

1 Skuse D. Non-organic failure to thrive: a reappraisal. Arch Dis Child 1985;60:173-8. 2 Budd K, McGraw T, Farbisz R, et al. Psycho-social concomitants of chidr
chol 1992;17:81-4.

3 Wittenburg JVP. Feeding disorders in infancy: classification and treatment considerations. Can f Psychiatry 1990;35: 529-33.

4 Blackman JA, Nelson CLA. Rapid introduction of oral feedings to tube fed patients. Dev Behav Pediatr 1987;8:63-7.

5 Geertsma MA, Hyams JS, Pelletier JM, Reiter S. Feeding resistance after parenteral hyperalimentation. Am $\mathcal{f} D$ is Child 1985;139:255-6.

6 Linscheid TR, Tarnowski KJ, Rasnake LK, Brams JS. Behavioural treatment of food refusal in a child with short gut syndrome. $¥$ Pediatr Psychol 1987;12:451-9.

7 Warady BA, Kriely M, Belkden B, Hellerstein S, Alan U. Nutritional and behavioural aspects of nasogastric tube futritional and behavioural aspects of nasogastric tube Perit Dial 1990;6:265-8.

8 Ramsay M, Gisel E, Boutry M. Non-organic failure to thrive: growth failure secondary to feeding-skills disorder. Dev Med Child Neurol 1993;35:285-97.

9 Butler NR, Golding J. From birth to five. A study of the health and behaviour of Britain's five year olds. London: Pergamon Press, 1986.

10 Pharaoh POD, Alberman ED. Annual statistical review. Arch Dis Child 1990;65:147-51.

11 Richman N, Stevenson J, Graham PJ. Pre-school to school: a behavioural study. London: Academic Press, 1982.

12 Chatoor I, Conley C, Dickson L. Food refusal after an incident of choking: a post traumatic eating disorder. $\mathcal{f} \mathrm{Am}$ Acad Child Adolesc Psychiatry 1988;27:105-10.

13 Douglas J. Behaviour problems in young children. London: Tavistock/Routledge, 1989.

14 Bazyk S. Factors associated with the transition to oral feeding in infants fed by nasogastric tubes. Am $\mathcal{F}$ Occup Ther 1990;44:1070-8.

15 Abidin RR. The parenting stress index. Windsor: NFER Nelson, 1990.

16 Gorman J, Leifer M, Grossman G. Non-organic failure to thrive. $\mathcal{F}$ Clin Child Psychol 1993;22:327-36.

17 Polan H, Leon A, Kaplan M, Kessler D. Disturbances of affect expression in failure to thrive. $\mathcal{F}$ Am Acad Child Adoaffect expression in failure to thrive.
lesc Psychiatry 1991;30:897-903.

18 Brown GW, Harris T. The social origins of depression. London: Tavistock, 1978

19 Stein A, Stein J, Walters EA, Fairburn C. Eating habits and attitudes among mothers of children with feeding disorders. $B M \mathcal{F}$ 1995;310:1995. 